\title{
Representações negativas do envelhecimento na comunicação pública brasileira: Campanha de Conscientização da Violência Contra a Pessoa Idosa no Trânsito
}

\author{
Negative representations of aging in brazilian public communication: \\ Awareness Campaign of Violence Against Older Persons in Traffic
}

\section{Denise Regina Stacheski}

Mestre e doutoranda em Comunicação e Linguagens pela Universidade Tuiuti do Paraná (UTP), professora da Escola de Comunicação e Artes da Pontifícia Universidade Católica do Paraná (PUCPR), Curitiba, PR - Brasil, e-mail: denisereginastacheski@gmail.com

\section{Resumo}

O artigo tem como objetivo verificar representações negativas dos idosos por meio de um recorte midiático, vinculado ao diálogo da comunicação pública (Estado, governo e os cidadãos), no Brasil. São referenciados autores nas áreas do envelhecimento (BEAUVOIR, 1990; DEBERT, 1999; PAPALÉO NETTO, 2007 ; GROISMAN, 1999; ELIAS, 2001; NERI, 2004; JARDIM, 2007), da comunicação pública (DUARTE, J., 2009; MATOS, 2009; BRANDÃO, 2009; ZEMOR, 1995) e de aspectos sociais (THOMPSON, 1998; BAKHTIN, 1997; GOFFMAN, 2008). De forma metodológica, a análise de conteúdo de Bardin (1995), pelo viés qualitativo, será o método norteador do estudo. No decorrer do artigo são apresentadas dez notícias publicadas por mídias impressas brasileiras, captadas do clipping da Campanha de Conscientização da Violência contra Pessoa Idosa no Trânsito do Governo Federal do Brasil, no ano de 2010.

Palavras-chave: Comunicação pública. Envelhecimento. Idosos. Representações sociais. 


\begin{abstract}
The article aims to examine negative portrayals of older people through a media clipping, linked to processes of public communication media (state, government and citizens) in Brazil. Are referenced authors in the areas of aging (BEAUVOIR, 1990; DEBERT, 1999; ELIAS, 2001; NERI, 2004; GARDEN, 2007), public communication (DUARTE, J., 2009; MATOS, 2009; BRANDÃO, 2009; ZEMOR, 1995; GIACOMIN, 2011) and social aspects (THOMPSON, 1998; BAKHTIN, 2007; GOFFMAN, 2008). In order methodological content analysis of Bardin (1995), the qualitative bias, the method will be guiding the study. Throughout the article, the ten news published by Brazilian print media, captured the clipping of the Campanha de Conscientização da Violência contra Pessoa Idosa no Trânsito, Brazil, in 2010.
\end{abstract}

Keywords: Public communication. Aging. Elderly. Social representations.

\section{O envelhecimento e as representações sociais da velhice}

Com o envelhecimento populacional brasileiro, discussões sobre a qualidade de vida dos idosos começam a ser exploradas em todas as áreas de conhecimento. Apesar dos progressos-ocorridos nos últimos anos, por meio de movimentos públicos voltados à população idosa -, ainda falta uma comunicação pública mais eficaz para que a visão social do idoso seja positivada em nossa coletividade.

Debert (1999) afirma que o crescimento da população idosa no Brasil, nos últimos anos, não veio acompanhado de qualquer estrutura de suporte ao idoso e alerta para o fato de que, nas últimas décadas, o empreendimento de novas iniciativas voltadas para a terceira idade é proporcional à precariedade dos mecanismos de que dispomos para lidar com os problemas da velhice avançada. Por isso a necessidade de crescente reflexão social sobre esse segmento populacional que coloca em jogo múltiplas dimensões sociais, como o desgaste fisiológico, o prolongamento da vida, o desequilíbrio demográfico e o custo financeiro das políticas sociais.

O objetivo deste artigo é verificar representações negativas do idoso, por meio de um recorte midiático, vinculado aos processos de diálogo da comunicação pública (Estado, governo e os cidadãos) no Brasil. Entendemos que as representações negativas estão entrelaçadas com demais visões da velhice, postas em sociedade, como o envelhecimento bem-sucedido, por exemplo (STACHESKI; MASSI, 2011). No entanto, as representações negativadas ainda são maioria nas expressões midiáticas da comunicação pública. A metodologia utilizada é a análise de conteúdo de Bardin (1995), pelo viés qualitativo, por meio de unidades de contextos previamente selecionadas - explicitadas adiante.

O maior desafio, segundo Giacomini (2011, p. 1), é a politização do cidadão brasileiro para incluir entre seus objetivos: "o direito à velhice com dignidade; o direito a políticas de cuidado que contemplem a família que possui ou cuida de pessoas vulneráveis; o direito à promoção do envelhecimento ativo ao longo de todo o ciclo da vida". É preciso implementar de forma eficiente, o diálogo com a população idosa, no Brasil, é necessário implementar estratégias de comunicação social eficientes, "com ampla visibilidade e articulação com movimentos sociais, entidades governamentais e não governamentais, conselhos de direitos e setoriais e conselhos estaduais e municipais de idosos" (GIACOMINI, 2011, p. 1). Um diálogo mais próximo entre o Estado e a sociedade sobre questões que afetam o envelhecimento. Para a autora, "não reconhecer o envelhecimento da população brasileira é assumir riscos para as futuras gerações de jovens e velhos" (GIACOMINI, 2011, p. 1).

Groisman (1999) argumenta que a velhice como um problema social não pode ser compreendida como o resultado mecânico de modificações demográficas, mas sim como uma construção social. O julgamento hostil do envelhecimento, na atualidade, é fruto de uma contextualização histórica, social da humanidade, pois a concepção geral da velhice-assim como da infância, da adolescência - é cultural e é constituída por meio dos costumes diários de cada 
sociedade (PAPALÉO NETTO, 2007). Beauvoir (1990) confirma que cada sociedade cria seus próprios valores e é no contexto social que o conteúdo da palavra "declínio", tão vinculado à velhice, nos dias de hoje, adquire um sentido preciso.

As expressões midiáticas são centrais para a sociedade contemporânea, pois contribuem para a informação e o debate de temas de relevância social, incluindo o Estado, o governo e a sociedade. Para Matos (2010, p. 1), a mídia, a partir de uma vertente, desempenha seu papel de comunicador público quando: "informa, fiscaliza, discute, debate, critica, analisa, explica, interpreta, acusa e cobra". As palavras e os conteúdos midiáticos penetram e circulam nas relações sociais, nos encontros fortuitos da vida cotidiana, na interação mais imediata. Os sujeitos refletem os fatos exteriores produzidos e divulgados pela mídia e refratam na medida das significações de outros campos sociais, como uma cadeia de enunciações, uma cadeia constitutiva de valores. Na interação, entre o sujeito e a informação midiática, acontece, também, a constituição de significados a partir de uma eterna negociação de valores, de significados, de manifestações simbólicas que formam a cultura de uma sociedade.

As representações sociais, a partir das quais o idoso se constitui, transcendem as evidentes alterações físicas e fisiológicas do sujeito, estão inseridas em um contexto cultural. Podemos afirmar que a constituição dos idosos, inclusive do que é ser e experimentar a velhice, hoje, adquire forma e existência a partir de signos e significações criados pela coletividade.

Assim, por meio de interações verbais e não verbais acontecem as construções discursivas dos conteúdos midiáticos que interferem na sociedade e nos sujeitos que a compõem. Neste entrelaçar de vozes sociais, que são constituídas no dia a dia, nos laços que construímos, a exposição midiática é fundamental - principalmente para a comunicação pública.

\section{A comunicação pública e a população idosa}

Conceituar a comunicação pública não é fácil. É um campo complexo, em plena construção de significados. Refere-se a estratégias que visam ativar, incentivar, sistematizar diálogos e a formatar um processo comunicativo entre o Estado, o governo e a sociedade. No Glossário de Comunicação Pública, de Duarte e Veras (2006, p. 26), a revisão do conceito de comunicação pública, realizado por Heloiza Matos e Elizabeth Brandão, congrega os seguintes itens: a participação do Estado, do Governo, da Sociedade, do Terceiro Setor, a localização da esfera pública e a fundamentação do interesse público - ao fundamentar a comunicação pública como "o processo de comunicação, instaurado em uma esfera pública que engloba o Estado, governo, sociedade, um espaço de debate, negociação e tomada de decisões relativas à vida pública do país". Comunicação pública e cidadania, um campo de negociação - no qual as medidas de interesse público são debatidas e encontram decisões legítimas democraticamente.

Para M. Y. Duarte (2009), a comunicação pública é o elo da interação, do conhecimento. Sujeitos sociais que são atores que geram, transformam, buscam, usam e disseminam informações de variados tipos, circulando suas significações e representações diárias.

\section{Análise de conteúdo midiático: Campanha de Conscientização da Violência contra a Pessoa Idosa no Trânsito}

A metodologia selecionada foi a análise de conteúdo, fundamentada, principalmente, por Bardin (1995). A intenção da análise de conteúdo é analisar as inferências relativas às condições de produção nos processos comunicativos e nas enunciações realizadas. Inferências estas que recorrem a indicadores, neste artigo, qualitativos. Para Bauer e Gaskell (2004), a análise de conteúdo trabalha com textos escritos que já foram utilizados para algum outro propósito. Entendemos que a análise de conteúdo parte de uma constituição sócio-histórica dos enunciados, pois são produzidos socialmente e estão carregados de sentidos vivenciais. Ou como afirma Demo (2004, p. 25), "o contexto da fala é um contexto social marcado por correlações de força". E continua: "o primeiro ímpeto da fala não é comunicar, mas influir".

O objeto empírico deste artigo é a Campanha Nacional de Conscientização sobre a 
Violência no Trânsito contra a Pessoa Idosa ${ }^{1}$, do ano de 2010. Uma campanha pública nacional desenvolvida por órgãos do Governo Federal do Brasil. Em 11 de junho de 2010, a Secretaria de Direitos Humanos da Presidência da República (SDH/PR, 2010), o Conselho Nacional dos Direitos do Idoso (CNDI) e as seguintes entidades: Agência Nacional de Transportes Terrestres (ANTT), Serviço Social do Transporte (SEST), Serviço Nacional de Aprendizagem do Transporte (SENAT), Associação Nacional das Empresas de Transportes Urbanos (NTU) e Associação Brasileira das Empresas de Transporte Terrestre de Passageiros (ABRAT) lançaram a Campanha de Conscientização da Violência contra a Pessoa Idosa no Trânsito, que era o foco principal da Campanha Nacional de Conscientização sobre a Violência contra a Pessoa Idosa (2010). O objetivo principal era conscientizar a coletividade sobre a violência contra os idosos, no trânsito. O conteúdo da campanha foi destinado aos transportes coletivos urbanos e semiurbanos. A campanha do Governo Federal teve uma repercussão em vários meios de comunicação por todo o Brasil. E, alguns municípios, atrelaram a campanha, até mesmo, com outros eventos e iniciativas locais - para conscientizar a população da violência existente contra o idoso. A partir desse evento foi realizado, pela SDH/PR, um clipping das principais unidades noticiosas publicadas sobre a Campanha Nacional de Conscientização contra a Pessoa Idosa, no período de 14 a 17 de junho de 2010, em meios de comunicação, totalizando 95 notícias vinculadas ao tema. Foram selecionadas um grupo de 10 notícias, para este artigo, por meios dos seguintes critérios: as notícias deveriam ter conteúdos além do release prévio da campanha; deveriam ter depoimentos de idosos ou estatísticas locais; deveriam ter sido publicadas em mídias impressas que não se concentrassem em apenas uma região do país.

As notícias selecionadas foram analisadas a partir de duas categorias das vozes sociais do envelhecimento: com significações positivadas e significações negativadas do envelhecimento. Assim, a partir dos objetos empíricos selecionados foi realizada uma exploração de unidades de contexto. O intuito foi verificar expressões que se articulassem com as visões sociais do envelhecimento categorizadas para este artigo. As unidades de contexto foram selecionadas e classificadas como:

a) Expressões que abordam o idoso ou o processo de envelhecimento de forma negativada. Exemplos: Denúncias de violência; Violência social; Negligência Sofrida; Abandono e Isolamento; Agressão Física; Agressão Verbal; Apropriação de Bens Indevidas; Ameaças Verbais ou Físicas; Parentes como Agressores; Vítima de Maus-tratos; Vítimas Sociais; Silêncio; Discriminação e Preconceito; Desrespeito; Fragilidade Física; Doença e Velhice; Perda.

b) Expressões que abordam o idoso ou o processo de envelhecimento de forma positivada. Exemplos: Bemestar; Reivindicação; Felicidade; Paz e Harmonia; Respeito Social; Direitos dos Idosos; Relacionamentos Saudáveis; Relacionamentos por Idosos; Grupos Sociais; Festas e Comemorações; Amizades; Participação Social; Discussão Pública; Ações Intergeracionistas; Alegria para Viver; Experiência de Vida; Voz Social; Poder Aquisitivo.

Das dez notícias analisadas neste artigo, oito (8) estão alocadas na categoria das significações negativadas do envelhecimento e, apenas, duas (2), têm significações vinculadas a expressões positivadas do envelhecimento. Vale ressaltar que esta categorização tem um caráter metodológico, pois as visões sociais do envelhecimento se entrelaçam dialogicamente no cotidiano (Quadro 1).

Percebemos que uma visão negativa em relação ao processo do envelhecimento está inserida dentro das notícias publicadas, enaltecendo um estereótipo de isolamento e aversão social. A seguir, a apresentação e a análise desenvolvida das notícias selecionadas.

\footnotetext{
${ }^{1}$ Não encontramos os materiais gráficos oficiais da Campanha Nacional - apenas materiais regionais, que aderiram ao movimento.
} 
Quadro 1 - Expressões Negativadas e Expressões Positivadas - Clipping

\begin{tabular}{|c|c|c|}
\hline \multicolumn{3}{|c|}{ Impresso } \\
\hline \multicolumn{3}{|c|}{ Expressões Negativadas } \\
\hline Mídia / Localização & Título & Data de Publicação \\
\hline $\begin{array}{l}\text { 1. Jornal O Globo } \\
\text { Rio de Janeiro }\end{array}$ & População na Terceira Idade. & $16 / 06 / 2010$ \\
\hline $\begin{array}{l}\text { 2. Jornal Correio Brasiliense } \\
\text { Distrito Federal }\end{array}$ & Respeito e Gentileza de Carona. & $16 / 06 / 2010$ \\
\hline $\begin{array}{l}\text { 3. Jornal de Brasília } \\
\text { Distrito Federal }\end{array}$ & Dia de Combate da Violência. & $17 / 06 / 2010$ \\
\hline $\begin{array}{l}\text { 4. Jornal Gazeta do Povo } \\
\text { Curitiba }\end{array}$ & Respeito aos Idosos. & $17 / 06 / 2010$ \\
\hline $\begin{array}{l}\text { 5. Jornal do Tocantins } \\
\text { Palmas }\end{array}$ & $\begin{array}{l}\text { Idosos reivindicam direitos } \\
\text { e respeito em manifestação. }\end{array}$ & $15 / 06 / 2010$ \\
\hline $\begin{array}{l}\text { 6. Jornal Diário do Nordeste } \\
\text { Fortaleza }\end{array}$ & $\begin{array}{l}\text { Idosos silenciam sobre } \\
\text { violência na família. }\end{array}$ & $16 / 06 / 2010$ \\
\hline $\begin{array}{l}\text { 7. Jornal Diário de Natal } \\
\text { Natal }\end{array}$ & A dor silenciosa dos idosos. & $15 / 06 / 2010$ \\
\hline $\begin{array}{l}\text { 8. Jornal Pioneiro } \\
\text { Porto Alegre }\end{array}$ & Idosos têm sido vítimas de violência. & $15 / 06 / 2010$ \\
\hline \multicolumn{3}{|c|}{ Expressões Positivadas } \\
\hline $\begin{array}{l}\text { 9. Jornal Diário de Petrópolis } \\
\text { Petrópolis }\end{array}$ & $\begin{array}{l}\text { Campanha combate desrespeito } \\
\text { ao idoso no transporte público. }\end{array}$ & $15 / 06 / 2010$ \\
\hline $\begin{array}{l}\text { 10. Tribuna da Bahia } \\
\text { Salvador }\end{array}$ & $\begin{array}{l}\text { Caminhada alerta sobre violência } \\
\text { contra idosos. }\end{array}$ & $17 / 06 / 2010$ \\
\hline
\end{tabular}

Fonte: SDH/PR (2010).

Notícia 01: Jornal O Globo. Data: 16/06/2010. Título: População na terceira idade. Rio de Janeiro

Apresentação: A notícia afirma que Copacabana, segundo a Secretaria Municipal de Envelhecimento Saudável e Qualidade de Vida, tem a maior concentração de idosos não só do Estado do Rio de Janeiro, mas de toda a América Latina. Segundo publicação, "dos 147.021 habitantes do bairro, 27,5\% estão acima dos 60 anos. Os dados são do Instituto Pereira Passos (IPP) e têm como base o censo de 2000. Segundo a informação repassada na notícia, a média de Copacabana é maior do que o dobro do percentual do município, que tem $13,7 \%$ da população na terceira idade - ou 805.637. A cidade apresenta o maior percentual do país, assim como o estado, que tem 14,9\% de idosos, ou 2,3 milhões de pessoas". A seguir, o texto afirma que a Secretaria de Envelhecimento Saudável recebeu 524 denúncias envolvendo pessoas da terceira idade $-19 \%$ mais que as 440 registradas em 2008 - e que, entre os tipos de queixa, em primeiro lugar aparece a negligência, com $24 \%$ dos casos. Depois vêm abandono (19\%), agressão física (16\%), agressão verbal (13\%), apropriação de bens $(12 \%)$ e ameaça $(8 \%)$. A violência, segundo a notícia, quase sempre ocorre em casa e, em $70 \%$ dos casos, a vítima mora com o agressor. A publicação traz dados alarmantes sobre o cotidiano de violência entre idosos, o que sugere uma visão negativa da velhice - generalizada -, bem como do pouco respeito que os velhos recebem quando chegam à terceira idade. Outro dado destacado na notícia é que, em $95 \%$ das queixas, $70 \%$ da violência é ocasionada pelos filhos, amedrontando o idoso perante sua própria família.

Análise: Esta notícia apresenta dados que demonstram, e fortalecem, uma representação negativa, um estigma do envelhecimento na sociedade brasileira. Descasos da própria família para com o idoso. O isolamento social também é tratado no texto, 
por meio das estatísticas de abandono, agressão física e verbal. A questão da anulação do papel social do idoso se percebe pelas ameaças e pelas apropriações de bens indevidas - ocorridas pela própria família. O idoso apresenta-se como um estigma social (GOFFMAN, 2008). O estigma social se constitui quando a coletividade "estabelece os meios de categorizar as pessoas e o total de atributos considerados como comuns e naturais para os membros de cada uma dessas categorias" (GOFFMAN, 2008, p.12). Um atributo profundamente depreciativo, nesta notícia, o ser velho, a velhice - é uma relação entre um atributo e um estereótipo, uma ordem de significações produzida no dia a dia, nas interações comunicativas entre os membros de uma coletividade que, juntos, promovem a dinâmica da produção/reprodução da cultura em uma sociedade, assim como os valores do que é ser velho. Os sujeitos estigmatizados buscam resoluções para seu estado depreciativo, como meios para corrigir a fala, para clarear a cor da pele, para esticar o corpo, para restaurar a juventude, curas pela fé e outros meios existentes. No caso dos idosos, eles se tornaram estigmatizados numa fase avançada da vida, portanto, é provável que tenham maiores problemas em identificar-se e uma grande facilidade para se autocensurarem, para se menosprezarem.

\section{Notícia 02: Jornal Correio Brasiliense. Data: 16/06/2010. Título: Respeito e gentileza de carona. Jornalista: Flávia Foreque. Distrito Federal}

Apresentação: A notícia inicia com uma história ocorrida com a idosa, Rita Gomes da Silva, 61 anos. Enquanto procurava um assento no ônibus recebeu uma bronca do motorista pela quantidade de sacolas que carregava. Segundo depoimento da aposentada, no texto: "eu vinha com umas verduras de Águas Lindas [...]; não era tanta coisa assim, mas ele falou que velho não podia andar com tanta sacola [...]; o negócio é que eles não querem respeitar a gente". O texto informa que a violência contra o idoso no transporte público é o foco da Campanha Nacional de Conscientização sobre a Violência contra a Pessoa Idosa, coordenada pela Secretaria de Direitos Humanos da Presidência da República, em 2010.
Afirma que a proposta do governo é distribuir cartazes e folhetos informando aos idosos e aos motoristas a conduta ideal a ser seguida. A notícia traz também que, no Distrito Federal, um serviço criado, em agosto de 2009, vem garantindo mais respeito ao público idoso e que sob responsabilidade da Secretaria de Justiça, Direitos Humanos e Cidadania, o Disque-Idoso recebe denúncias de maus-tratos. O principal obstáculo dos atendentes que acolhem as queixas, segundo a notícia, é o fato de os próprios idosos retirarem, em pouco tempo, as queixas feitas ao serviço. "A gente lutou tanto pelo estatuto e agora o próprio idoso tem medo; não sabemos o tipo de coação que ele sofre em casa", lamenta Zilda Sanchez, em depoimento à notícia. Para o levantamento referido no texto, foi constatado que cerca de $70 \%$ das denúncias tratam de maus-tratos físicos. Este é o mesmo percentual de casos em que as filhas agridem as mães, alerta o conteúdo publicado. A notícia enfatiza: "em geral, aqueles que machucam os idosos são do próprio núcleo familiar".

Análise: Percebemos, no texto, questões sobre o estigma diante do processo de envelhecimento - permeando, inclusive, o ambiente familiar e colocando o idoso de forma frágil e vitimizada perante a coletividade. A partir do depoimento da idosa na notícia, sobre a fala do motorista - "velhos não podem carregar sacolas" -, salientamos que no cotidiano, e no sistema midiático, é comum a associação entre a velhice e a doença, a debilitação física. Esta forma de conceber o processo de envelhecimento pode trazer sentimentos de inferioridade e desgosto aos idosos. A mudança física atrelada ao declínio fisiológico fortalece a visão de que o envelhecimento é uma perda sem fim. As campanhas públicas de saúde, por exemplo, lançadas e trabalhadas pelos órgãos responsáveis pelos idosos, no Brasil, estão aumentando quantitativamente na última década, mas, em sua maioria, são planejadas pelo viés de prevenção de doenças advindas do envelhecimento; processos comunicativos voltados para uma análise quantitativa/estatística e para questões de prevenção de doenças advindas da idade avançada. Segundo Jardim (2007), os discursos presentes na nossa coletividade demonstram as perdas físicas, psíquicas e sociais do idosos. As perdas físicas são representadas pela fraqueza, diminuição de força e 
da vitalidade orgânica. As perdas psíquicas representadas pelo declínio da memória, pela anulação da vida afetiva e pelo desinteresse em construir novas relações e adquirir novos conhecimentos. As perdas sociais estão vinculadas como um ser não produtivo, um ser dependente, "à margem da construção da história em curso" (JARDIM, 2007). Uma visão do idoso que o toma como um peso social, reduzindo a velhice a uma situação desagradável.

\section{Notícia 03: Jornal de Brasília. Data: 17/06/2010. Título: Dia de Combate da Violência. Distrito Federal}

Apresentação: A notícia informa que a Secretaria de Justiça, Direitos Humanos e Cidadania (Seju), por meio da Subsecretaria para Assuntos da Terceira Idade (Subati), realizará diversas atividades para lembrar o Dia Mundial de Conscientização da Violência Contra a Pessoa Idosa no dia 15 de junho de 2010. Afirma que, no evento, serão oferecidas orientações na área jurídica, psicológica e social aos idosos. O encontro terá ainda aulas de capoterapia (movimentos inspirados na capoeira), aferição de pressão e nível de glicose. A notícia expõe que o Dia Mundial de Conscientização da Violência Contra a Pessoa Idosa foi instituído pela Organização das Nações Unidas (ONU), em 2006, visando romper o silêncio que envolve a violência contra o idoso. No Distrito Federal, por exemplo, traz o texto publicado, a violência no seio familiar chega a $70 \%$ dos casos denunciados por meio do Disque-Idoso, da Secretaria de Justiça. A maioria se refere a denúncia anônima e muitos idosos ainda pedem a retirada da reclamação com receio de prejudicar o agressor - quando filho ou neto - ou por se sentirem ameaçados.

Análise: A notícia salienta violências que idosos sofrem no núcleo familiar e o medo frente à denúncia da própria familia - pelos mau-tratos. Um reforço para uma visão negativa do envelhecimento. Para analisar a violência familiar para com o idoso, recorreremos a outra exposição midiática, a novela "Mulheres Apaixonadas", Rede Globo, 2003. A novela trouxe, na época, fortes apelos midiáticos sobre a violência contra os idosos (SOUSA, 2008). O fato exposto coincidiu com a discussão pública sobre a aprovação do Estatuto do Idoso, em 2003, que ampliava os direitos dos idosos em relação à Política Nacional do Idoso, lei anterior. Percebemos que a aprovação e a implantação do Estatuto do Idoso, de 2003, não conseguiu modificar - em todo - as rotinas de violência contra os idosos. O estigma social da velhice perdura na cultura brasileira, nas interações diárias, no sistema midiático, e é repassado pelas gerações - por meio de um contexto sócio-histórico.

\section{Notícia 04: Jornal Gazeta do Povo. Dia 17/06/2010. Título: Respeito aos idosos. Curitiba/ PR}

Apresentação: No Jornal Gazeta do Povo foi divulgado que "justamente quando chegam à idade em que mais precisam do apoio de seus familiares, as pessoas se tornam vítimas da violência doméstica". Segundo as informações da notícia, cerca de um terço da população idosa do Sul do país já foi vítima de algum tipo de delito. Há casos que envolviam negligência e abandono, agressões físicas e psicológicas e apropriação indébita de aposentadorias e outros bens. O texto salienta que "O Brasil, que até pouco tempo era um país de jovens, ainda não aprendeu a lidar com os idosos. E parece que está longe de encontrar o caminho certo. Como ativistas do Fórum Popular estão cobrando, é preciso resgatarmos valores familiares e fortalecermos a rede de proteção e atenção para conter a violência contra o idoso. Assim como existem canais de proteção à criança, está na hora de começarmos a dar o devido valor e atenção a nossos idosos".

Análise: A notícia traz a questão do resgate de valores e coloca que alguns idosos não conseguem ter uma rede de proteção familiar, fortalecendo os estereótipos de isolamento social. Destacamos que as sociedades, em sua maioria, transformadas em tecnocráticas com o advento da industrialização, enfraqueceram o julgamento positivo a respeito da experiência de vida dos mais velhos - o valor da tradição e da experiência. Beauvoir (1990, p. 257) afirma que "a sociedade tecnocrática de hoje não crê que, com o passar dos anos, o saber se acumula, mas sim que acabe perecendo". Nas sociedades industriais, o interesse é investir nos jovens, que, com sua força de trabalho física, garantem 
a produtividade por anos a fio, e as experiências vivenciadas pelos mais velhos não são valiosas, nesse sistema. Na civilização moderna ocidental, a tendência é que o envelhecimento seja posto como sinônimo de doenças e perdas, pois é vinculado a uma sociedade de consumo que reserva à velhice uma posição deficitária.

\section{Notícia 05: Jornal do Tocantins. Dia 15/06/2010. Título: Idosos reivindicam direitos e respeito em manifestação. Palmas/ TO. Jornalista: Tatiane Souza}

Apresentação: No Jornal do Tocantins, a notícia informa uma caminhada a ser realizada em alusão ao Dia Mundial de Combate a Violência Contra o Idoso. A representante do Conselho Estadual dos Direitos da Pessoa Idosa, citada no texto, Célia da Mata, afirma que o objetivo da passeata é sensibilizar a sociedade, o poder público e os idosos a denunciarem a violência. Segundo seu depoimento, “já tivemos alguns avanços na questão de violência contra o idoso, mas ainda temos muitos desafios, um deles, é construir um plano estadual de enfrentamento à violência contra o idoso". A notícia traz o relato de Lourival Prado, de 73 anos, que afirma: "estamos fazendo nossa parte que é preservar a vida, cuidar da saúde e respeitar o direito dos outros, mas as mensagens estão dizendo que os nossos direitos não estão sendo respeitados". A notícia informa também que, segundo a Secretaria Estadual da Saúde (Sesau), dados do Sistema Único de Saúde (SUS) apontam o Tocantins como o quinto Estado no ranking nacional em mortes violentas de pessoas idosas. A preocupação com a violência contra o idoso tem mobilizado lugares do mundo todo, tendo em vista o crescimento dessa população, enfatiza o texto publicado.

Análise: Salientamos que a violência pelo idoso, reforçada e retratada na notícia, envolve diversos aspectos econômicos, políticos e culturais - pode ser considerada, também, como uma forma de expressão dos múltiplos conflitos, de resistência, de lutas e de desigualdades que existem em nossa coletividade. Temos que levar em conta que o idoso, segundo Teixeira (2006, p. 61):

Sofre a opressão que se dá tanto pela desigualdade social e de classe, quanto ao confinamento social, dada pela segregação, pelas históricas políticas de assistência social em instituições asilares, que remontam ao século XVIII; como ao abandono ou isolamento pela família que, com as transformações capitalistas, perdem espaço enquanto unidade de produção e reprodução social, que tinham em sociedades anteriores, e se vêem exigidas a buscar os meios de sobrevivência no mercado de trabalho, sem condições de manter seus idosos, financeiramente e com cuidados.

Essa constituição sociocultural do envelhecimento está vinculada ao sistema de interação midiático, representando vozes sociais da velhice - postas na coletividade. Na última décadas, outras realidades surgem ante a velhice, mas a significação do que é ser velho ainda traz resquícios históricos. A questão da violência contra o idoso no Brasil é uma problemática social que se inscreve na sociedade, também, pela comunicação pública.

O envelhecimento populacional levanta novas demandas e necessidades aos idosos; e a tendência é que as lutas, as resistências e os movimentos ligados aos idosos e aos seus direitos se potencializem. Portanto, a questão da violência contra o idoso deixa de ficar restrita às esferas privadas, do cotidiano familiar, para se tornar pública e exigindo respostas do Estado e da sociedade no sentido do combate a essa violência.

\section{Notícia 06: Jornal Diário do Nordeste. Data: 16/06/2010. Título: Idosos silenciam sobre violência na família. Ceará. Jornalista: Mozarly Almeida}

Apresentação: O Diário do Nordeste apresenta sua notícia mostrando que a violência contra o idoso acontece de várias maneiras, com ênfase para agressões física e psicológica, negligência ou exploração financeira. Somente em Fortaleza, segundo o texto, o Centro de Referência Especializado da Assistência Social (Creas) contabilizou 1.272 denúncias de violência contra idosos residentes na capital, do ano de 2008 até 2010. Afirma, também, que no Dia Mundial de Conscientização da Violência às Pessoas Idosa, componentes de grupos de convivência promovidos pela STDS se reuniram, na Praça dos Estressados, na Avenida Beira-Mar, para dançar, praticar atividades físicas e cuidar da saúde. 
A programação do evento envolveu, ainda, panfletagem, serviços de verificação de pressão arterial e glicemia, sondagem de nível de estresse e memória, realização de atividades físicas e apresentação da banda de música "De Bem com a Vida", formada por idosos do Centro Comunitário Santa Terezinha.

Análise: Nesta notícia, percebemos que as atividades propostas pelo evento estão, em sua maioria, destinadas à ludicidade. Dessa forma, abordaremos a questão das atividades de entretenimento do idoso e do processo de infantilização. Grande parte dos trabalhos e projetos desenvolvidos no país para os idosos está voltada para o entretenimento ou para questões de prevenção de doenças advindas da idade avançada. É como se o envelhecimento não permitesse mais espaço para discutir decisões da família, da coletividade da sociedade em geral. É uma forma de infantilizar o idoso, é uma outra visão social em relação aos idosos, intrinsecamente ligada ao julgamento de anulação do papel social das pessoas mais velhas. Concebê-las como frágeis, merecendo atitudes e uma linguagens infantilizadas. Com esse julgamento de valor, a coletividade reforça uma fragilidade correspondente à velhice e os torna impotente, ao tratá-los como crianças. A capacidade de autonomia e de tomada de decisões dos idoso acaba sendo ferida e o idoso desrespeitado. O uso de diminutivos evidencia a ausência de papel social do idoso, lembrando que eles os não possuem condições para tomar suas decisões e que há a necessidade de alguém, a família, a instituição, o Estado, de comandar os próximos passos - seja em relação a sua moradia, a suas atividades, às suas falas, aos seus sentimentos, às suas organizações econômicas. Como se, de repente, com a velhice, os idosos perdessem a noção dos seus valores, de sua identidade, do seu modo de vida. Tendemos a utilizar uma linguagem infantilizada aos idosos, às vezes, com o objetivo de se ter uma conversa mais acalentosa, porém a infantilização da linguagem constitui a visão de dependência, de negação da velhice autônoma e da necessidade de transformar um idoso em "um bom velhinho" ou em "um coitadinho". Reforça, assim, a própria vitimização do idoso.

Notícia 07: Jornal Diário de Natal. Data: 15/06/2010. Título: A dor silenciosa dos idosos. Rio Grande do Norte. Jornalista: Andrielle Mendes
Apresentação: O Jornal Diário de Natal afirma "onde deveria existir um grito de basta, há silêncio". O texto enfatiza que o idoso sente vergonha, receio de denunciar e sofrer mais agressão; de reclamar e prejudicar um filho, um neto. Com receio de sofrer mais violência, alguns chegam a retirar a queixa antes de a polícia instaurar o inquérito ou logo após os agressores serem notificados. O perfil dos agressores é uma das causas da subnotificação. Segundo levantamento da Promotoria do Idoso, citado na notícia, os principais agressores são filhos e netos $-47 \%$. Isso mostra, de acordo com o texto, "que quem deveria proteger agride". Em seguida, vem a violência praticada nos hospitais, abrigos e transporte $-36 \%$ do total. Além da violência doméstica e no transporte, os idosos também sofrem com a retenção de cartões magnéticos e desvio da aposentadoria por familiares, conforme o texto publicado. Quando a polícia recebe a denúncia e tenta intervir, muitos se negam a receber ajuda e preferem ficar calados. A notícia afirma também que, de acordo com pesquisa do Ministério da Saúde em 2008, cerca de dois milhões de idosos são vítimas de agressão todo ano no Brasil. O estudo mostrou que as agressões eram a segunda causa de internação no SUS.

Análise: Importante salientar que toda matéria jornalística tem um processo de construção que pode ser pensada, como uma agenda possível, um olhar desejável, para os contextos sociais. Existe uma lógica jornalística na exposição dos fatos, na mídia - são descrições de experiências sociais, nas quais estão inseridas uma hierarquização de valores. O sistema de interação midiático e seu agenciamento frente o poder das representações; a partir disso percebermos que há, também, uma construção da vitimização da velhice pela mídia, pela comunicação pública. Os conteúdos expressam, muitas vezes, o idoso como um sujeito passivo diante das agressões sofridas. Como afirma a notícia: "onde deveria existir um grito de basta, há silêncio". Reforça, assim, a questão da anulação social do idoso - da relação entre fragilidade e a velhice - da impotência de refratar sua constituição vitimizada e doentia na coletividade. Toda vez que o termo "idoso" surge nas notícias, a atenção da comunidade é chamada, é uma fronteira de disputas sociais sobre a violência, sobre a segurança, sobre o futuro. 
Notícia 08: Jornal Pioneiro. Data: 16/06/2010. Título: Uma vítima a cada 2 dias. Rio Grande do Sul

Apresentação: O Jornal Pioneiro, do Rio Grande do Sul, afirma que a violência, contra os idosos, continua alta em Caxias do Sul e que os familiares são os principais responsáveis pela violação dos direitos individuais dos idosos. A constatação é baseada na quantidade de investigações abertas pelo Ministério Público (MP) de Caxias do Sul. A cada dois dias, em média, segundo a notícia, a 2.a Promotoria de Justiça Especializada instaura um procedimento para apurar denúncias graves como maus-tratos, negligência, omissão ou apropriação de bens e renda. Os dados, a partir do texto publicado, foram divulgados pelo promotor de Justiça Adrio Rafael Paula Gelatti. Entre 2008 e 2009, a quantidade de casos se manteve estável, totalizando 280 procedimentos no MP, uma média de 140 por ano. Naquele ano, porém, Gelatti já havia formalizado 93 investigações. $\mathrm{O}$ número é preocupante, pois indica um aumento um pouco acima do normal da intolerância contra a terceira idade, enfatiza o promotor, citado na notícia. As denúncias que chegam à 2.a promotoria são variadas: idosos abandonados, pessoas que se apoderam do benefício da aposentadoria, agressões físicas e psicológicas, entre outras. Geralmente, o autor é o familiar que convive mais próximo da vítima, salienta o texto.

Análise: Repetidamente, observamos o reforço à vitimização da velhice. Uma construção narrativa realizada pela mídia impressa - se apropriando de uma Campanha Pública - que também reforça visões negativas em relação ao envelhecimento. Como afirmam Agra do Ó; Souza; Costa e Almeida (2010): "o que temos percebido é a pregnância, no discurso jornalístico, de certa sensibilidade social em torno do envelhecimento humano. Tal sensibilidade é tecida com uma mescla heterogênea de fios, alguns marcados pelas cores dos estereótipos, outros pelos tons do reconhecimento dos direitos humanos da pessoa idosa, outros mais pelas sombras de uma sociabilidade vincada pela dureza e pela inclemência da barbárie".

Notícia 09: Jornal Diário de Petrópolis. Data: 15/05/2010. Título: Campanha combate desrespeito ao idoso no transporte público. Rio de Janeiro
Apresentação: $O$ texto informa que para combater o desrespeito aos idosos usuários do transporte público, a Secretaria de Direitos Humanos da Presidência da República lançaria a Campanha Nacional de Conscientização sobre a Violência contra a Pessoa Idosa, o qual marca o lançamento do Dia Mundial de Conscientização da Violência contra a Pessoa Idosa. O transporte coletivo urbano e semiurbano foi escolhido como tema da campanha, explica a notícia, porque tem sido alvo frequente de reclamações nos conse-lhos estaduais de Direitos do Idoso (CDI). A notícia traz a experiência do aposentado, Vitor Barros, 71 anos, morador do Guará II - região administrativa do DF: "Uma vez, puxei a cordinha para o ônibus parar e o motorista disse que só podia pedir para parar quem estava depois da catraca e tivesse pagado a passagem. Eu deveria esperar alguém descer para ir junto". Em outra ocasião, complementa a notícia, o aposentado solicitou para a cobradora lhe ceder o lugar, pois ela ocupava dois assentos no banco dos passageiros. A funcionária negou-se e o idoso procurou a empresa para denunciar o constrangimento. O idoso afirma: "carrego comigo o telefone de todas as empresas para reclamar se for preciso".

Análise: $\mathrm{Na}$ frase, "carrego comigo o telefone de todas as empresas para reclamar se for preciso", verificamos que existe um posicionamento de refração perante a vitimização proposta. Com isso, percebemos que não há como afirmar de maneira generalizada que envelhecer é sinônimo de doença e inativação, novos valores e conceitos estão sendo construídos na coletividade atual e estão sendo difundidos globalmente (LIMA; SILVA; GALHARDONI, 2008). Considerar que os velhos são igualmente sábios ou incapazes é uma concepção negativa, pois envelhecer é um evento progressivo e de múltiplas facetas que pode ser vivido como uma experiência positiva, bem-sucedida ou negativa, com mais ou menos qualidade de vida, ou pode ser vivido no encontro e desencontro do bom e do ruim a partir dos diferentes momentos de vida (DEBERT, 1999). Muito além de aspectos como engajamento com a vida, habilidades funcionais e cognitivas, hábitos saudáveis, o envelhecimento bem-sucedido tem relação direta com as dimensões socioculturais e coletivas, com as subjetividades no âmbito individual e particular. O envelhecimento não se traduz apenas em perdas biológicas, mas em ganhos que advêm da 
experiência acumulada, valorizar a velhice é valorizar a própria vida humana em sua plenitude. No entanto, em contraponto, como afirma Elias (2001, p. 80):

Não é fácil imaginar que nosso próprio corpo, tão cheio de frescor e muitas vezes de sensações agradáveis, pode ficar vagaroso, cansado e desajeitado. Não podemos imaginá-lo e, no fundo, não o queremos. Dito de outra maneira, a identificação com os velhos e com os moribundos compreensivelmente coloca dificuldades especiais para as pessoas de outras faixas etárias. Consciente ou inconscientemente, elas resistem à idéia de seu próprio envelhecimento e morte tanto quanto possível.

\section{Notícia 10: Tribuna da Bahia. Dia 17/06/2010. Título: Caminhada alerta sobre violência contra idosos. Salvador}

Apresentação: A notícia informa que seria realizada, na referida data, uma caminhada, entre as praças da Piedade e Municipal, pelos idosos baianos para protestar contra a violência da qual são vítimas. A iniciativa, segundo a publicação, integrava a programação da semana anual de Conscientização para o Enfrentamento à Violência contra a Pessoa Idosa, promovida pela Secretaria da Justiça, Cidadania e Direitos Humanos do Estado (SJCDH) e o Conselho Estadual do Idoso. Após a caminhada, a notícia informa que os idosos participariam de uma sessão especial na Câmara de Vereadores de Salvador, na qual discutiriam as violências cometidas contra o idoso no estado, principalmente nos transportes públicos, responsáveis por grande parte das reclamações feitas nos órgãos de proteção ao idoso.

Análise: Embora a notícia traga os aspectos do estigma social da velhice - reforçando a vitimização do idoso -, destacamos, aqui, o movimento da "caminhada" de protesto e a participação dos idosos na sessão da Câmara de Vereadores de Salvador. Parece existir uma revolta do próprio grupo idoso ante seu estigma social, refletindo e refratando a sua condição social no envelhecimento. Idosos à procura de expressão e de voz social. Um dos meios, atualmente, existentes no Brasil, são os Conselhos dos Idosos - que são organizados nas três esferas federativas: municipal, estadual e nacional. São órgãos consultivos, deliberativos, controlador e fiscalizador, que têm como objetivo garantir o cumprimento das diretrizes da Política Nacional do Idoso para assegurar direitos em diversas áreas, tais como previdência, saúde, cultura e educação, trabalho e lazer. Sua composição é paritária - para cada representante do governo existe um membro da sociedade civil. Os Conselhos dos Idosos ${ }^{2}$ são atores sociais - que se fortalecidos e legitimados podem ser aliados no processo de novas políticas públicas aos idosos. Mas, como indaga Borges (2009, p.13), "até onde se dá, de fato, a participcação dessa parcela da população na definição e controle nas políticas públicas no Brasil?" Concordamos que a participação de idosos, em instâncias de controle social, representa uma conquista ao segmento populacional - que ainda se encontra vulnerável socialmente. No entanto, os Conselhos ainda se encontram em processo de construção e de consolidação. Buscam, também, um espaço maior para que possam, verdadeiramente, se transformar em um canal de voz para os idosos.

\section{Considerações finais}

E assim, no entrelaçar das contradições se encontra o idoso brasileiro.

A comunicação pública brasileira ainda não encontra caminhos para trabalhar na elevação da autoestima do velho brasileiro, no reconhecimento de seu papel como cidadão, na reivindicação plena de seus direitos, na adoção de uma postura mais autônoma e na busca de uma percepção mais ampliada da comunidade onde vive.

\footnotetext{
2 Borges (2009, p. 60) explica que a organização de conselhos de direitos dos idosos nos níveis locais pode ser um dos indicadores do grau de maturidade do movimento social que representa a população idosa. Tanto é assim que, mesmo antes de se ter uma legislação nacional que cria os espaços participativos no âmbito do Estado Brasileiro, alguns conselhos estaduais já se haviam se organizado. $O$ Conselho Estadual de São de Paulo talvez seja o caso emblemático, pois ele foi criado antes da promulgação da Constituição Federal. Instituído em 1987, o Conselho do Idoso do Estado de São Paulo reflete o grau de organização dos trabalhadores e aposentados ao longo da década de oitenta, afinal, esse estado reúne grande parte dos trabalhadores da indústria do País.
} 
O envelhecimento é um processo diferenciado entre os sujeitos, único de acordo com cada indivíduo. Acreditamos que este é um dos mais fortes paradigmas a ser quebrado nos julgamentos de valores que ecoam na sociedade: a velhice não é homogênea; estabelecer padrões engessados a respeito do envelhecimento apenas produz ações superficiais na constituição do envelhecer. Podemos citar como alguns dos elementos que interferem e constituem o processo de envelhecimento: o gênero do idoso, a classe social, a saúde, a educação, os fatores de personalidade, as práticas de comunicação e interações sociais, a história passada e o contexto socioeconômico. O envelhecimento, pelo contexto sócio-histórico, nunca foi homogêneo, assim como nenhuma outra fase da vida - em nenhuma sociedade. O processo da velhice é antes de tudo o reflexo da experiência individual: "os que foram bem-sucedidos ao longo de toda a sua vida gozarão, sem dúvida, de prestígio; os demais ficarão expostos e terão que conviver com o desafeto e a falta de respeito dos parentes e vizinhos". Cada sujeito vai elaborar esquemas e estratégias de adaptação pessoal à velhice. Esses esquemas serão o reflexo de toda a sua história de vida, de suas significações, portanto, poderão ser mais ou menos construtivos e socialmente positivos.

O entendimento do que é o envelhecimento, portanto, acontece na conjuntura cultural, no sistema de valor social, nos sistemas e nos processos de comunicação, nas relações e nos julgamentos entre os sujeitos idosos e os demais segmentos populacionais. Verificamos que na circulação das unidades noticiosas, divulgadas pela imprensa, no permear da comunicação pública, em todo o território brasileiro, a violência contra os idosos tem grande expressão. A visão negativa da velhice e a intolerância ao envelhecimento se torna uma forte representação social. Vozes que estão presentes nos meios de comunicação (jornais, televisão, revistas, meios digitais), nas relações comerciais e mercadológicas cotidianas, nas redes familiares, em uma conversa informal uma pequena comunidade, em todas as nossas interações verbais cotidianas, das quais constituímos nossos valores (BAKHTIN, 1997).

\section{Referências}

AGRA DOÓ, A. Norbert Elias e uma narrativa acerca do envelhecimento e da morte. História, Ciências, Saúde. Manguinhos [online], v. 15, n. 2, p. 389-400, 2008.

AGRADOÓ, A.;SOUZA, R. N.;COSTA,T.; ALMEIDA, V. B.. A violência contra idosos na mídia: uma reflexão sobre a produção dos sentidos. Revista Famecos, Porto Alegre, v. 17, n. 1, janeiro/abril , 2010, p. 121-129.

BAKHTIN, M. Marxismo e filosofia da linguagem. São Paulo: Hucitec, 1997.

BARDIN, L. Análise de conteúdo. Rio de Janeiro: Edições 70, 1995.

BEAUVOIR, S. de. A velhice. Rio de janeiro: Nova Fronteira, 1990.

BORGES, A. P. Representação da população idosa na luta por seus direitos no Brasil: o caso dos Conselhos Estaduais do Idoso. Dissertação. 2009. (Dissertação) Programa de Pós-Graduação Stricto Sensu em Gerontologia da Universidade Católica de Brasília, Brasília, 2009.

BRANDÃO, E. Conceito de comunicação pública. In: DUARTE, J. (Org.). Comunicação pública: estado, mercado, sociedade e interesse público. São Paulo: Atlas, 2009. p. 1-33.

DEBERT, G. G. A reinvenção da velhice. São Paulo: Edusp, 1999.

DEMO, P. Desafios modernos da educação. $13^{\text {a }}$ edição. Petrópolis, RJ. Vozes. 2004.

DUARTE, J. (Org.). Comunicação pública: estado, governo, mercado, sociedade e interesse público. São Paulo: Atlas, 2009.

DUARTE, J.; VERAS, L. Glossário de comunicação. Brasília: Casa das Musas, 2006.

DUARTE, M. Y. Comunicação e cidadania. In:DUARTE, J. (Org.). Comunicação pública: estado, mercado, sociedade e interesse público. São Paulo: Atlas, 2009a. p. 95-115.

ELIAS, N. A solidão dos moribundos: seguido de “envelhecer e morrer". Rio de Janeiro: Jorge Zahar. 2001. 
GIACOMINI, K. C. Direitos do idoso na elaboração e implementação de políticas públicas no Brasil. Revista dos Direitos da Pessoa Idosa, 2011. Disponível em: $<$ http://portal.mj.gov.br/sedh/3cndpi/doc/Revista_ DireitosPessoa_Idosa.pdf>. Acesso em: jun. 2012.

GOFFMAN, E. Estigma: notas sobre a manipulação da identidade deteriorada. Rio de Janeiro, Guanabara, 2004.

GROISMAN, D.. Asilos de velhos: Passado e Presente. Estudos Interdisciplinares sobre o envelhecimento. v. 17, n. 2, 2012.

JARDIM, S. E. G. Aspectos socioeconômicos do envelhecimento. In: PAPALEO NETTO, M. Tratado de gerontologia. 2.ed. rev. e ampl. São Paulo: Atheneu, 2007. p. 30 - 51.

LIMA, A. M. M.; SILVA, H. S.; GALHARDONI, R. Successful aging: paths for a construct and new frontiers. Interface. Comunicação, Saúde, Educação, Botucatu, v. 12, n. 27, p. 795-807, out./dez. 2008.

MATOS, H. Capital social e comunicação. interfaces e articulações. São Paulo: Summus, 2009.

MATOS, H. O potencial do capital social na comunicação pública. Observatório de Imprensa, v.16, n.698, 2010. Disponível em: <http://www.observatoriodaimprensa. com.br/news/view/o-potencial-do-capital-social-na-comunicacao-publica>. Acesso em: maio 2012.

NERI, A. L. O que a psicologia pode oferecer ao estudo e à intervenção no campo do envelhecimento no Brasil, hoje. In Neri, A. L. \& Yassuda, M. S. (orgs). Velhice bem sucedida. Campinas, SP: Papirus, 2004. p. 113-140.

PAPALEONETTO, M. Tratado de gerontologia. 2.ed. rev. e ampl. São Paulo: Atheneu, 2007.

SECRETARIA ESPECIAL DOS DIREITOS HUMANOS DA PREVIDÊNCIA DA REPÚBLICA (SDH/PR). Presidência da República Federativa do Brasil. Pessoa Idosa. Campanha Nacional de Conscientização sobre a Violência contra a Pessoa Idosa (2010). Disponível em: <http://www.direitoshumanos.gov. br/2010/06/11-jun-2010-campanha-nacional-promove-conscientizacao-sobre-violencia-contra-idosos>. Acesso em: jun. 2011.
SOUSA. J. Obrigado por/a ser feliz: as representações dos idosos nas telenovelas brasileiras. Intercom - Sociedade Brasileira de Estudos Interdisciplinares da Comunicação. Trabalho apresentado no XXXI Congresso Brasileiro de Ciências da Comunicação. Natal, RN, 2 a 6 set. 2008. Disponível em: <http://www.intercom.org. $\mathrm{br} /$ papers/nacionais/2008/resumos/R3-0342-1.pdf>. Acesso em: jan. 2010.

STACHESKI, D. R.; MASSI, G. A. Índices sociais de valor: mass media, linguagem e envelhecimento. Revista Interface, v.15, 2011. Disponível em: <http://submission.scielo.br/index.php/icse/article/view/30699>. Acesso em: jun. 2011.

TEIXEIRA, S. M. Envelhecimento do trabalhador no tempo do capital. 2006. Tese (Doutorado em Políticas Públicas) - Universidade Federal do Maranhão, São Luís, 2006.

THOMPSON, J. B. A mídia e a modernidade: uma teoria social da mídia. Petrópolis: Vozes, 1998.

WOLF, M. Teorias da comunicação. Lisboa: Presença, 1987.

ZÉMOR, P. La communication publique. Tradução livre e resumida da obra realizada pela professora Elizabeth Brandão. Paris: PUF, 1995. (Col. Que sais-je?). Disponível em <http://www.ucb.br/comsocial/ $\mathrm{mba} /$ ComunicacaoPublicaPierreZémor_traducao.pdf $>$. Acesso em: maio 2012.
Recebido: 10/11/2012

Received: 11/10/2012

Aprovado: 19/10/2012

Approved: 10/19/2012 